\title{
7. How to ensure adequate investment in power plants?
}

\section{Leonardo Meeus with Athir Nouicer}

In this chapter, we answer three questions. First, why did some countries introduce a capacity mechanism? Second, what is the best capacity mechanism? Third, how to limit the (ab)use of capacity mechanisms?

\subsection{WHY DID SOME COUNTRIES INTRODUCE A CAPACITY MECHANISM?}

Capacity mechanisms were introduced to ensure adequate investment in power plants. Today we talk about resource adequacy rather than generation adequacy because we also have demand and storage solutions that can compete with power plants in these mechanisms. However, in some parts of this chapter, we still focus on power plants or generation because that is how we used to talk about this issue. The mechanisms are called capacity mechanisms because they provide payment for capacity (MW) in addition to wholesale markets that remunerate energy (MWh). Electricity markets without capacity mechanisms are sometimes referred to as energy-only markets. This is misleading because electricity markets without capacity mechanisms also include capacity components. Retail contracts typically include capacity components, and the same is true for balancing capacity markets. In what follows, we focus on the main arguments that have been used in favour of capacity mechanisms. First, we explain how the economic arguments in favour of capacity mechanisms are evolving from missing money to missing markets. Second, we argue that the real reason that most countries go for capacity mechanisms is political rather than economical.

First, the evolution from the missing money argument in favour of capacity mechanisms to the missing markets argument. ${ }^{1}$ Electricity demand is relatively inflexible and electric energy storage capacities are still limited, so prices can go up and down depending on the availability of renewable energy sources and the demand for electricity. The California crisis in the early 2000s showed that companies can sometimes abuse their market power by driving up electricity prices. ${ }^{2}$ Around that time, most US electricity markets introduced price caps to limit this market power abuse. However, this caused some power plants to lose money, typically the plants that were only needed to cover peak demand. These so-called peakers ran for a limited number of hours a year. In these hours, they not only had to recover their fuel and other operating costs, but they also needed to earn a margin that was large enough to cover their capital costs. If not, they would go out of business. As the price caps were applied equally to all periods of the year, they also reduced the peakers' income in times of scarcity. This resulting loss of income was termed 'the missing money problem'. Note that the initial focus was on 
price caps, but later it was realized that missing money in wholesale and balancing markets can also be caused by other interventions. For instance, in Chapter 5 we discussed how capacity payments to reserve balancing services can distort the scarcity price signal close to real time. The missing money problem was the main reason why most US wholesale markets introduced a capacity mechanism at the beginning of this century. The situation in Europe was somewhat different, and we will come back to it in the next section.

The counter-argument is that capacity mechanisms are not needed. It is simply necessary to fix the interventions that cause the missing money. For instance, structural measures can be applied to improve competition so that price caps can be removed and balancing markets can be reformed. However, there is also a missing market problem in electricity markets. In Chapter 2, we discussed cross-border hedging in the forward timeframe. The contract length for transmission rights goes up to a year, while companies typically want to hedge with longer-duration contracts. In Chapter 6, we referred to technical requirements in connection agreements that could become markets for system services. Another missing market is the market for reliability. If there is a shortage in the electricity market, rationing is applied. Certain districts are disconnected for a few hours, and then other districts for a few hours, so the pain is spread with what is referred to as a rolling blackout. Unlike a real blackout, this one is planned and scheduled. In Box 7.1 we discuss a controversy in Belgium around a rationing plan when the country came close to having to use it. The problem with the rationing approach is that those who caused the shortage are not held accountable. If retailers knew that their customers would be cut off if they do not secure enough supply, they would have more incentives to enter into long-term contracts with investors in power plants. As long as this is not fixed, it is another argument in favour of a capacity mechanism to ensure that we have adequate investment.

Second, the politics of capacity mechanisms. ${ }^{3}$ Capacity mechanisms have often been lobbied for by incumbents. These mechanisms are also appealing to risk-averse policymakers who do not want to be blamed for electricity shortages. In Europe, the number of countries that have introduced a capacity mechanism increased after the global financial and economic crisis that started in 2008. Most of the big utilities in Europe had invested substantially in new gas-fired power plants. Many of these plants did not run in the years following the crisis because electricity demand stopped growing or even reduced, and renewable energies had grown faster than expected. In this context, capacity mechanisms became controversial. Some argued they are simply state aid to national champions that have made the wrong investment decisions, while others argued they keep alive the gas plants that we desperately need as backup capacity for renewable energy sources.

\section{BOX 7.1 RATIONING OR LOAD-SHEDDING PLANS AND CONTROVERSIES}

In Belgium, a load-shedding plan led to controversy in the media and in court in 2014. In the winter of 2014-2015 several nuclear plants were unavailable, so the country risked having to use the plan. The general public learned about the plan from the media, which started to publish maps in six different colours indicating which regions would be cut off first.

Load-shedding plans organize controlled power outages. They make it possible to avoid a much more serious situation, such as a general blackout of a region. The rationing is usu- 
ally limited in time. Some sites, such as hospitals, are classified as priority and are never cut. The Belgian plan also avoided city centres and communities with more than 50000 inhabitants as well as capitals of provinces.

The main controvesy arose in the port of Ghent and the airports of Liège and Charleroi, which were included in or were close to blue zones - the zones that were first to be cut off. Ghent demanded that the port area be excluded from the load-shedding plan. The City of Ghent and the company responsible for managing the port (Havenbedrijf Gent) launched a court case against the parties involved: the Ministers of Economy and Energy, the transmission system operator (TSO) Elia and the distribution system operator (DSO) IMEWO. The City asked for $€ 10$ million compensation in the case of load shedding. The airports of Liège and Charleroi also had similar concerns.

Note: Commission de l'économie (2015) summarizes the debate that took place in 2015 regarding load-shedding plans in Belgium. CREG (2016) presents the modifications in the load-shedding plans that were decided on following the incident.

\subsection{WHAT IS THE BEST CAPACITY MECHANISM?}

There are many ways to implement a capacity mechanism, and the relative popularity of the different options clearly evolved with experience. In what follows, we discuss the experiences of Spain, Sweden, Great Britain and Ireland, which together nicely illustrate what Europeans think about capacity mechanisms. We present a taxonomy of capacity mechanisms in Annex 7A.1.

First is the case of Spain, which has been well-documented and commented on by our colleagues. ${ }^{4}$ Spain introduced a capacity mechanism as early as 1997 . The capacity price was administratively set by the regulator and the government. In 2007, the mechanism included two components: investment incentives and availability payments. The investment subsidy was then $€ 28000 / \mathrm{MW} /$ year. In 2012, the price was reduced from $€ 28000$ to $€ 23000 / \mathrm{MW} /$ year. In 2013, it was further reduced to $€ 10000$, but the period over which the capacity payments applied was extended from 10 years to 20 years. The investment incentives were only for generation capacity installed between 1998 and 2016. In 2018, availability payments for capacity rewarding combined cycle gas turbines (CCGTs), natural gas, fuel-oil, coal-fired and hydropower generators were suppressed. The Spanish government's reason was to be in line with the Clean Energy Package and the energy transition objectives. This Spanish mechanism is called capacity payments. A few more countries like Ireland, Italy and Greece also tried out this mechanism, but it is being abandoned by all of them in favour of mechanisms that set the price in a market for capacity.

Second is the case of Sweden. Since 2004, it has been possible for power plants to be strategically reserved in Sweden. There is an administrative decision to reserve a certain amount of capacity, and the price of that capacity is set in an auction. Power plants that would otherwise be taken offline can then stay on the system and be used in times of shortages. This mechanism became the most popular mechanism in Europe, even though it received much criticism. The fear was that governments or regulators would be tempted to use their strategic reserves to reduce price peaks. This would then act as a de facto price cap in wholesale markets and cause a missing money problem for the other power plants that did not receive a capacity payment 
from the strategic reserve fund. In Sweden, reserve activation only happens if there is a curtailment situation in Sweden or Finland. TSOs in both countries decide together which resources to use in the case of shortages. Note that today a large part of the Swedish strategic reserve is demand response from load-heavy industry.

Third is the case of Great Britain. Since 2014, Great Britain has had a US-style capacity auction, often referred to as a capacity market. There is an administrative decision to procure a certain amount of capacity, and the price of that capacity is set in an auction. The capacity market applies to all the power plants or resources able to provide capacity. The problem with such a mechanism is that it distorts the wholesale market. The wholesale market is a European market in which power plants from different countries compete, as was explained in Chapter 2 , but some of them are now supported by national capacity mechanisms while others are not. Within a national market with a capacity mechanism, the mechanism also distorts the level playing field between different players and technologies. In the past these mechanisms focused on supporting power plants, while today supply solutions are wanted to compete with demand and energy storage solutions. It has proven to be very difficult to design capacity mechanisms that are technology-neutral. The so-called Tempus case illustrates the controversies around these mechanisms (Box 7.2).

\section{BOX 7.2 THE TEMPUS CASE}

Tempus, a demand response provider, argued that the capacity market scheme in Great Britain discriminated against demand response. The mechanism had been approved by the European Commission, which was challenged by Tempus. In 2018 the General Court of the European Union issued a judgment in case T-793/14 'Tempus Energy Ltd and Tempus Energy Technology Ltd $v$ Commission' overruling the Commission's decision to approve the state aid scheme establishing a capacity market in the United Kingdom (UK). The UK government suspended the capacity market to comply with the judgment. This led to an immediate stopping of the existing capacity payments and the cancelling of 2019 auctions.

The European Commission appealed against the decision and conducted a state aid investigation. The UK government supported the Commission's appeal. After an in-depth investigation, in October 2019 the Commission again approved the mechanism. It confirmed that it complied with the EU state aid rules and that it did not distort competition in the single market. The investigation did not find evidence that the capacity market scheme would put demand response providers at a disadvantage. At the same time, the UK government committed to improving the scheme, considering recent market and regulatory developments and other issues identified in the UK government's 2019 five-year review of the capacity market. This includes, for instance, revisiting the minimum capacity size to participate in the auction and the rules on participation by new types of players. Tempus can still challenge the re-approval, and other related proceedings are still ongoing.

Note: $\quad$ Before the Clean Energy Package was adopted, the European Commission instruments to control the implementation of capacity mechanisms were the EU state aid rules. Our colleagues Hancher et al. (2015) are experts on state aid and provide a detailed discussion of experiences with capacity mechanisms. 
Fourth is the case of Ireland. Ireland started with Spanish-style capacity payments but became the first country in Europe to introduce reliability options. This is a mechanism that has been advocated by academics as superior to capacity markets because it pays for the availability of capacity at times of shortages rather than paying for capacity. Reliability options are based on the concept of a call options contract, and capacity providers enter into an option contract with a counterparty (a TSO or a large consumer or supplier). This contract offers the counterparty the option of procuring electricity at a predetermined strike price. In return for the premium paid - the price of the option contract - the counterparty gets insurance against high prices. This premium then replaces the capacity remuneration. The mechanism incentivizes power plants or other players to have resources available when prices go up. If they do not, they will have to buy energy at the high prices in the market and sell it at the lower strike price that has been agreed when entering the insurance scheme. In addition, regulators may apply further safeguards with a penalty for non-compliance and/or by requiring a certain level of physical capacity for all options sold. By design, this mechanism is less distorting for the wholesale market than capacity markets. However, when we looked into the implementation details, we found that many parameters are still set administratively. These include who can offer which amount of reliability options, the length of the contract and many other factors that are known to favour some solutions over others. ${ }^{5}$

In other words, there is no best design for capacity mechanisms. If a country is fully convinced its electricity market cannot survive without a capacity mechanism, reliability options are the most elegant design option, but it will need to keep a close eye on the implementation details. If it is not convinced but political reality pushes it towards an intervention to safeguard the availability of capacity in the system, strategic reserves will be its preferred option. They are easier to implement and the Clean Energy Package includes provisions that remedy the main risks associated with strategic reserves, as we will discuss in the next section.

\subsection{HOW TO LIMIT THE (AB)USE OF CAPACITY MECHANISMS?}

The Clean Energy Package goes a long way towards limiting the (ab)use of capacity mechanisms. Regulation (EU) 2019/943 introduced two steps to check if capacity mechanisms are really needed and also includes provisions to guide the design of these mechanisms.

\subsubsection{Is a Capacity Mechanism Really Needed?}

Here, we introduce the European resource adequacy assessment and the national implementation plan for market reforms, both of which will be used to check whether a certain country needs a capacity mechanism.

First, the European resource adequacy assessment. Following Regulation (EU) 2019/943, this assessment will be used to check if there is a need for concern. The assessment is to be carried out every year by ENTSO-E based on data provided by national TSOs and cover a period of ten years. A European assessment can avoid over-reaction if a certain country has an issue which can be solved by its neighbours. It can also avoid under-reaction if a number of countries are counting on the same neighbour and/or over-estimate the capacity of their neighbours to help in certain situations. Member States can also continue to do national assess- 
ments, which they can use to complement the European assessment with additional sensitivity analysis. If this leads to disputes, a process has been foreseen with a role for the Agency for the Cooperation of Energy Regulators (ACER).

Regulation (EU) 2019/943 introduced a process to come up with a methodology that will be used in these assessments. The role of the Member States or a competent authority designated by them is to define a reliability standard. The reliability standard is the level of risk countries want to take to face shortages, which is expressed as the 'expected energy not served' (EENS), or the 'loss of load expectation' (LOLE). The role of the European Network of Transmission System Operators for Electricity (ENTSO-E), with oversight from ACER, is to integrate this standard into a methodology that also considers the cost of new entry of generation, or demand response, and the cost people face when they do not have electricity, which is expressed as the value of lost load (VoLL). Scenarios with demand and supply projections will also need to be agreed upon to be able to perform this assessment. In December 2019, ENTSO-E launched two public consultations to collect inputs from stakeholders on the proposal for the EU resource adequacy assessment methodology and on the VoLL, the cost of a new entry and the reliability standard calculation methodology.

Second, the national implementation plan for market reforms. As discussed in the previous sections, much can be done to reduce the need for capacity mechanisms. Price caps can be removed in wholesale markets and retail markets, more investment can be made in the transmission network and balancing markets can be reformed, as was discussed in Chapter 5. Following Regulation (EU) 2019/943, Member States with identified resource adequacy concerns need to develop and publish an implementation plan with a timeline for adopting measures to eliminate any identified market distortions. The plans will be reviewed by the European Commission, which shall issue an opinion within four months. Member States also have to monitor the application of their plans and publish the results of the monitoring in an annual progress report.

Regulation (EU) 2019/943 refers to capacity mechanisms as measures of last resort to eliminate residual resource adequacy concerns. Member States are to carry out a study of the possible effects of capacity mechanisms on neighbouring countries before they are implemented. They are also to prioritize assessment of the potential of a strategy reserve mechanism to address residual resource adequacy concerns. Only if strategic reserves cannot address them may Member States implement other types of capacity mechanisms.

Capacity mechanisms are also to be temporary and to be approved by the European Commission for a maximum of ten years. Then they are to be phased out, or the amount of committed capacity is to be reduced according to the national market reform implementation plan. Member States are to continue the application of the implementation plan after the introduction of the capacity mechanism. They need to include a provision allowing for an efficient administrative phase-out in the case that no new contracts are concluded for three consecutive years. Member States are to review capacity mechanisms that are already in place. If the resource adequacy assessments have not identified concerns, no new contracts under these mechanisms are to be concluded. 


\subsubsection{Design Principles for Capacity Mechanisms}

Regulation (EU) 2019/943 provides guidance to Member States regarding the design of capacity mechanisms. Below, we discuss the design principles that apply to all mechanisms, and specific ones that apply to strategic reserves.

First is technology neutrality. Capacity mechanisms need to be open to participation by all capable resources, including demand and storage solutions and decentralized energy resources. Resources should be selected through a transparent non-discriminatory competitive process. The mechanisms must also provide incentives for participants to be available in times of system stress when they are most needed. Appropriate penalties should be applied for providers who are not available during such times.

Second are strategic reserves. Strategic reserves are only to be dispatched in the case that TSOs are likely to exhaust their balancing resources. During imbalance settlement periods in which resources in the strategic reserve are dispatched, the imbalances in the market are to be settled at least at the VoLL or at a higher value than the intraday technical price limit, whichever is higher. Following the dispatch, the strategic reserve's output is to be attributed to balance responsible parties (BRPs) through the imbalance settlement mechanism. In addition, the resources participating in the strategic reserve mechanism shall not receive any remuneration from wholesale or balancing markets. They are to be held outside the market at least during the contractual period.

Third are $\mathrm{CO} 2$ emission limits. Capacity mechanisms cannot be abused to subsidize the most polluting coal power plants. A grandfathering clause was introduced for capacity mechanism contracts that were concluded before 31 December 2019. Since 4 July 2019, a CO2 emission limit of $550 \mathrm{~g}$ of $\mathrm{CO} 2$ of fossil fuel origin per $\mathrm{kWh}$ has been applied for new generation capacity. Additionally, from 1 July 2025, an emission limit of $350 \mathrm{~kg}$ of CO2 of fossil fuel origin on average per year per installed $\mathrm{kWe}$ for existing capacity is applied, that is, generation capacity that started commercial production before 4 July 2019. In December 2019, ACER published an opinion providing technical guidance related to the calculation of the values of $\mathrm{CO} 2$ emission limits for capacity mechanisms. It clarifies the scope of application of the emission limits and sets out the calculation formulae and the related specifications.

Fourth is cross-border participation. Capacity mechanisms other than strategic reserves must be open to explicit cross-border participation to limit distortions to cross-border trade and competition and to provide incentives for interconnection investment to ensure the EU security of electricity supply at the least cost. Cross-border participation in strategic reserves is to be open where technically feasible. With ACER oversight, ENTSO-E needs to develop a methodology to calculate the maximum entry capacity for cross-border participation. TSOs are then to set the maximum entry capacity for foreign capacity on the basis of a recommendation by the regional coordination centre. Many more details will be worked out to enable cross-border participation in capacity mechanisms.

\subsection{CONCLUSION}

In this chapter on how to ensure adequate investment in power plants, we have answered three questions. First, why did some countries introduce a capacity mechanism to ensure adequate investment in power plants? The arguments in favour of capacity mechanisms are evolving 
from missing money to missing markets. The missing money problem was first identified in the US, where price caps had led to a reduction in generation unit incomes, especially those of peakers. Missing markets include longer-term hedging across borders and the market for reliability. We also showed that the real reason behind capacity mechanisms is often political rather than economical.

Second, what is the best capacity mechanism? We discussed the experiences of Spain with capacity payments, Sweden with strategic reserves, GB with capacity markets and Ireland with reliability options. We cannot say that there is an absolute winner. Nevertheless, there is a trend towards strategic reserves, which is reflected in the Clean Energy Package framework for capacity mechanisms.

Third, how to limit the (ab)use of capacity mechanisms? We presented the new regulatory framework introduced in the Clean Energy Package. It includes EU resource adequacy assessment and national implementation plans for market reforms. Member States need to check whether it is sufficient to introduce strategic reserves, and detailed design principles for these reserves are provided. The new framework also encompasses other design principles for capacity mechanisms, such as technology neutrality, $\mathrm{CO} 2$ emission limits and rules on cross-border participation.

\section{NOTES}

1. Shanker (2003) used the missing money concept in his reaction to the standard market design proposals by the Federal Energy Regulatory Commission (FERC) in the US. Cramton and Stoft (2006) have also been influential in their study of the issue. Joskow (2008) went a step further and argued that the missing money is not only caused by price caps but there are other market interventions that have the same effect. Examples include actions by system operators to ensure system reliability. Newbery (1989) discusses the missing market problem when revenue is adequate but not perceived, that is, the commodity being sold is considered a public good. Bhagwat et al. (2016) present a survey of US experts regarding capacity mechanisms. The answers are in favour of energy-only markets. Cretì and Fontini (2019) highlight the pros and cons of the different capacity mechanisms. They provide an alternative tool to capacity mechanisms: the operating reserve demand curve, which complements energy-only markets. This tool is also discussed in Hogan (2013), who argues that it can complement both energy-only markets and markets with capacity mechanisms. We referred to this approach in Chapter 5.

2. The California crisis in 2000-2001 is one of the most iconic electricity market crises. Several academics from the US have analysed the California crisis including Borenstein (2002), Borenstein et al. (2003, 2008), Joskow $(2001,2008)$ and Wolak (2003). In 1998, the state had introduced competitive wholesale and retail markets for electricity. It was the first fully decentralized market arrangement, with a power exchange (CALPX) and an independent system operator (CAISO), in the US. CAISO operated the transmission networks owned by the three major utilities and ran various energy-balancing, ancillary services and congestion management markets, while CALPX ran both a voluntary day-ahead and hourly hour-ahead public wholesale markets for energy. Note that the three largest utilities had a (largely unhedged) obligation to trade on the day-ahead and real-time markets operated by the PX and the ISO. Wholesale market prices were deregulated, while retail prices were fixed for up to four years. The reforms assumed that wholesale prices would be lower than the administrative cap set for the retail price. As it turned out, markets appeared to be quite competitive in periods with low and moderate demand. However, demand had been increasing rapidly in the previous years, while there had been little new investment. As a result, in periods of high demand a combination of tight supplies and inelastic demand created opportunities for individual generators to exercise market power. Between May 2000 and June 2001, California experienced an explosion in wholesale power prices, followed by supply shortages and rolling blackouts with 
physical rationing by the ISO. In January 2001, CALPX declared itself bankrupt after it had been unable to implement mitigation measures imposed by the regulator. California responded to the crisis with costly long-term contracts of up to 20 years negotiated by the state, long-term obligations for procurement, a freeze on retail competition and, overall, by taking some step backs from a fully decentralized market model. The California crisis even made it into the documentary on the Enron bankruptcy The Smartest Guys in the Room.

3. Thomas-Olivier Léautier (2019) argues that capacity mechanisms owe more to the political economy than to microeconomics. He argues that elected officials prefer a zero-blackout criterion irrespective of the costs incurred. He also argues that most system operators, regulators and government employees are in favour of an increase in their scope of intervention through the design and monitoring of capacity mechanisms. These employees are the first to be blamed by politicians in the case of blackouts.

4. In Batlle et al. (2007) and Batlle and Pérez-Arriaga (2008) our colleagues share their views on the Spanish and international experiences with capacity mechanisms.

5. The concept of reliability option was first outlined by Pérez-Arriaga (1999). Vázquez et al. (2002) discuss the experience of Colombia with this mechanism. Oren (2005) also promotes the concept. In Bhagwat and Meeus (2019) we discuss the implementation of reliability options in Ireland and Italy.

\section{REFERENCES}

ACER (2013), 'Capacity Remuneration Mechanisms and the Internal Market for Electricity'.

Batlle, C. and I. J. Pérez-Arriaga (2008), 'Design criteria for implementing a capacity mechanism in deregulated electricity markets', Utilities Policy, 16 (3), 184-93.

Batlle, C., C. Vázquez, M. Rivier and I. J. Pérez-Arriaga (2007), 'Enhancing power supply adequacy in Spain: Migrating from capacity payments to reliability options', Energy Policy, 35 (9), 4545-54.

Bhagwat, P. and L. Meeus (2019), 'Reliability options: Can they deliver on their promises?', Electricity Journal, 32 (10).

Bhagwat, P. C., L. J. de Vries and B. F. Hobbs (2016), 'Expert survey on capacity markets in the US: Lessons for the EU', Utilities Policy, 38, 11-17.

Borenstein, S. (2002), 'The trouble with electricity markets: Understanding California's restructuring disaster', Journal of Economic Perspectives, 16 (1), 191-211.

Borenstein, S., J. Bushnell, C. R. Knittel and C. Wolfram (2008), 'Inefficiencies and market power in financial arbitrage: A study of California's electricity markets', Journal of Industrial Economics, 56 (2), 347-78.

Borenstein, S., J. Bushnell and F. A. Wolak (2003), 'Measuring market inefficiencies in California's restructured wholesale electricity market', American Economic Review, 92 (5), 1376-405.

Commission de l'économie (2015), 'Débat Sur Le Plan de Délestage' ['Debate on the Shedding Plan'], accessed at https://www.dekamer.be/doc/CCRI/pdf/54/ic044x.pdf.

Cramton, P. and S. Stoft (2006), 'The Convergence of Market Designs for Adequate Generating Capacity', Report for California Electricity Oversight Board, accessed at https://doi.org/10.1007/ s13398-014-0173-7.2.

CREG (2016), 'Rapport Annuel 2015' [Annual Report 2015'].

Cretì, A. and F. Fontini (2019), 'Investing in power generation', in Economics of Electricity: Markets, Competitions and Rules, Cambridge: Cambridge University Press, pp. 259-98.

EP (2017), 'Capacity Mechanisms for Electricity', accessed at http://www.europarl.europa.eu/RegData/ etudes/BRIE/2017/603949/EPRS_BRI(2017)603949_EN.pdf.

Hancher, L., A. de Hauteclocque and M. Sadowska (ed.) (2015), Capacity Mechanisms in the EU Energy Market: Law, Policy, and Economics, Oxford: Oxford University Press.

Hogan, W. W. (2013), 'Electricity scarcity pricing through operating reserves', Economics of Energy and Environmental Policy, 2 (2).

Joskow, P. (2001), 'California's electricity crisis', Oxford Review of Economic Policy, 17 (3), 365-88.

Joskow, P. (2008), 'Lessons learned from electricity market liberalization', Energy Journal, 29 (Special Issue \#2), 9-42. 
Léautier, Thomas-Olivier (2019), ‘The highly visible hand: Capacity mechanism', in Imperfect Markets and Imperfect Regulation, Cambridge, MA: MIT Press, pp. 325-59.

Newbery, D. M. (1989), 'Missing markets: Consequences and remedies', in F. H. Hahn (ed.), The Economics of Missing Markets, Information, and Games, Oxford: Clarendon Press, pp. 211-42.

Oren, S. S. (2005), 'Generation adequacy via call options obligations: Safe passage to the promised land', Electricity Journal, 18 (9), 28-42.

Pérez-Arriaga, I. J. (1999), 'Reliability and generation adequacy', in W. S. Read, W. K. Newman, I. J. Pérez-Arriaga, H. Rudnick, M. R. Gent and A. J. Roman (1999), 'Reliability in the new market structure (Part 1) ', IEEE Power Engineering Review, 19 (12), 4-5.

Shanker, R. (2003), 'Comments on Standard Market Design: Resource Adequacy Requirement. Federal Energy Regulatory Commission', accessed at http://elibrary.ferc.gov/idmws/common/opennat.asp ?fileID $=9619272$.

Vázquez, C., M. Rivier and I. J. Pérez-Arriaga (2002), 'A market approach to long-term security of supply', IEEE Transactions on Power Systems, 17 (2), 349-357.

Wolak, F. A. (2003), 'Diagnosing the California electricity crisis', Electricity Journal, 16 (7), 11-37. 


\section{A.1 ANNEX: TAXONOMY OF CAPACITY MECHANISMS}

\section{Table 7A.1 Taxonomy of capacity mechanisms}

\begin{tabular}{|c|c|c|}
\hline \multicolumn{2}{|c|}{ Type } & $\begin{array}{l}\text { Taxonomy of capacity mechanisms based on EP (2017) and ACER (2013) } \\
\text { Strategic reserve: A central agency (transmission system operator or a government agency) decides on } \\
\text { the amount of capacity needed to make up any shortfall in the market a few years in advance. The level } \\
\text { of payment for the contracted capacity (strategic reserve) is set through a competitive tendering process. }\end{array}$ \\
\hline & 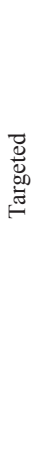 & $\begin{array}{l}\text { Strategic reserve: A central agency (transmission system operator or a government agency) decides on } \\
\text { the amount of capacity needed to make up any shortfall in the market a few years in advance. The level } \\
\text { of payment for the contracted capacity (strategic reserve) is set through a competitive tendering process. } \\
\text { The contracted power plants cannot participate in the electricity market and are only activated in the case } \\
\text { of extreme conditions. The } 2016 \text { Commission Sector Inquiry highlighted a strategic reserve as the most } \\
\text { appropriate mechanism for circumstances where temporary or local adequacy concerns are identified. } \\
\text { Capacity obligation: Also called capacity requirement, this is an obligation on suppliers or large consumers } \\
\text { to contract with generators for a certain level of capacity related to their self-assessed future consumption or } \\
\text { supply (e.g. three years ahead) plus a reserve margin that is decided on by an independent body. If not } \\
\text { enough capacity is contracted, the supplier or the consumer will pay a buy-out price/fine. The price for } \\
\text { capacity is determined in a decentralized way through the contracts. This model can also include a market for } \\
\text { exchangeable obligations (secondary market). }\end{array}$ \\
\hline & & $\begin{array}{l}\text { Capacity auction: The capacity volume to be auctioned is decided centrally (by the TSO or regulator) and } \\
\text { totally a few years in advance. The price is determined by auction and is paid to all resources (existing and } \\
\text { new) clearing the auction. Capacity providers bid to receive a payment that reflects the cost of building new } \\
\text { capacity. The new capacity participates in the energy-only market. }\end{array}$ \\
\hline 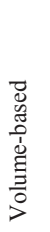 & 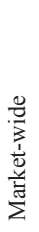 & $\begin{array}{l}\text { Reliability options: This mechanism is based on a forward auction (e.g. three years ahead). A capacity } \\
\text { provider enters into an option contract with a counterparty (a TSO or a large consumer or supplier). The } \\
\text { contract offers the counterparty the option to procure electricity at a predetermined strike price. The capacity } \\
\text { provider must be available to the system operator for dispatch above the strike price. In the } 2016 \text { Commission } \\
\text { Sector Inquiry, reliability options were highlighted as the most appropriate mechanism where long-term } \\
\text { adequacy concerns are identified. }\end{array}$ \\
\hline 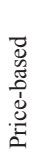 & & $\begin{array}{l}\text { Capacity payments: This is a price-based mechanism. It pays a fixed amount (set by the regulator) for the } \\
\text { capacity available to all generators. The plants receiving capacity payments continue to participate in the } \\
\text { energy-only market. The payment can also be made when the plant does not run, but certain availability } \\
\text { criteria have to be met. }\end{array}$ \\
\hline
\end{tabular}




\section{A.2 ANNEX: REGULATORY GUIDE}

\section{Table 7A.2 Regulatory guide}

Section of this chapter, topic and relevant regulation

\section{Section 7.3.1}

Regulation (EU) 2019/943 introduces a binding EU resource adequacy assessment. It can be complemented with national assessments.

Regulation (EU) 2019/943 sets the coverage and duration of the EU resource adequacy assessment together with ENTSO-E's role in its conduct.

Regulation (EU) 2019/943 provides a development process for the draft methodology for the EU resource adequacy assessment and the principles underlying it.

Regulation (EU) 2019/943 requires the development of a methodology for VoLL, cost of new entry and reliability standards.
Relevant article

\author{
Rever
}

Art. 20(1) states that 'Member States shall monitor resource adequacy within their territory on the basis of the European resource adequacy assessment referred to in Article 23. For the purpose of complementing the European resource adequacy assessment, Member States may also carry out national resource adequacy assessments pursuant to Article 24.'When a resource adequacy concern is identified in an assessment, Art. 20(2) states that '... the Member State concerned shall identify any regulatory distortions or market failures that caused or contributed to the emergence of the concern.'

Art. 23(1) states that 'the European resource adequacy assessment shall identify resource adequacy concerns by assessing the overall adequacy of the electricity system to supply current and projected demands for electricity at Union level, at the level of the Member States, and at the level of individual bidding zones, where relevant. The European resource adequacy assessment shall cover each year within a period of 10 years from the date of that assessment.' Art. 23(2) adds that 'the European resource adequacy assessment shall be conducted by the ENTSO for Electricity.'

Art. 23(3) states that 'by 5 January 2020, the ENTSO for Electricity shall submit to the Electricity Coordination Group set up under Article 1 of Commission Decision of 15 November 2012 and ACER a draft methodology for the European resource adequacy assessment based on the principles provided for in paragraph 5 of this Article.'

Among the principles underlying the EU adequacy assessment which are to be ensured by the transparent methodology, Art. 23(5) states that the assessment is to be carried out at each bidding zone level. It is to be based on appropriate central reference scenarios of projected demand and supply. In addition, the methodology must ensure that the assessment 'appropriately takes account of the contribution of all resources including existing and future possibilities for generation, energy storage, sectoral integration, demand response, and import and export and their contribution to flexible system operation.' Moreover, the assessment should apply at least the 'expected energy not served' (EENS) and the 'loss of load expectation' (LOLE) indicators, which are referred to in Art. 25 .

Art. 23(6) states that 'by 5 January 2020, the ENTSO for Electricity shall submit to ACER a draft methodology for calculating:

(a) the value of lost load;

(b) the cost of new entry for generation, or demand response; and

(c) the reliability standard referred to in Article 25 .

The methodology shall be based on transparent, objective and verifiable criteria.' 


\begin{tabular}{l} 
Section of this chapter, topic and relevant \\
regulation \\
\hline According to Regulation (EU) $2019 / 943$, the \\
reliability standard aims to reflect the level of \\
the security of supply of the Member States. \\
Regulation (EU) $2019 / 943$ sets principles for \\
the calculation of the reliability standard.
\end{tabular}

Regulation (EU) 2019/943 provides a guide for the development and publication of national implementation plans for market reforms.
Relevant article

Art. 25(1) states that 'when applying capacity mechanisms Member States shall have a reliability standard in place. A reliability standard shall indicate the necessary level of security of supply of the Member State in a transparent manner. In the case of cross-border bidding zones, such reliability standards shall be established jointly by the relevant authorities.'Art. 25(2) adds that 'the reliability standard shall be set by the Member State or by a competent authority designated by the Member State, following a proposal by the regulatory authority ...' In addition the reliability standardis to be '... calculated using at least the value of lost load and the cost of new entry over a given timeframe and shall be expressed as "expected energy not served" and "loss of load expectation"'(Art. 25(3)).

Art. 20(3) lists the principles that are to be taken into account when addressing adequacy concerns. It states that 'Member States with identified resource adequacy concerns shall develop and publish an implementation plan with a timeline for adopting measures to eliminate any identified regulatory distortions or market failures as a part of the State aid process. When addressing resource adequacy concerns, the Member States shall in particular take into account the principles set out in Article 3 and shall consider:

(a) removing regulatory distortions;

(b) removing price caps in accordance with Article 10;

(c) introducing a shortage pricing function for balancing energy as referred to in Article 44(3) of Regulation (EU) 2017/2195;

(d) increasing interconnection and internal grid capacity with a view to reaching at least their interconnection targets as referred in point (d)(1) of Article 4 of Regulation (EU) 2018/1999;

(e) enabling self-generation, energy storage, demand side measures and energy efficiency by adopting measures to eliminate any identified regulatory distortions;

(f) ensuring cost-efficient and market-based procurement of balancing and ancillary services;

(g) removing regulated prices where required by Article 5 of Directive (EU) 2019/944.'

Regulation (EU) 2019/943 sets out a process for the submission and review of implementation plans.
Art. 20(4) states that the Member States concernedshall 'submit their implementation plans to the Commission for review.'Then, 'within four months of receipt of the implementation plan, the Commission shall issue an opinion on whether the measures are sufficient to eliminate the regulatory distortions or market failures that were identified pursuant to paragraph 2, and may invite the Member States to amend their implementation plans accordingly' (Art 20(5)). The application of the implementation plans shall be monitored by the Member States concerned, as is stated in Art. 20(6). An annual report on the results of the monitoring is to be published by the Member States concerned and submitted to the Commission, which 'shall issue an opinion on whether the implementation plans have been sufficiently implemented and whether the resource adequacy concern has been resolved'(Art. 20(7)). Finally, Art. 20(8) states that 'Member States shall continue to adhere to the implementation plan after the identified resource adequacy concern has been resolved.' 


\begin{tabular}{l} 
Section of this chapter, topic and relevant \\
regulation \\
\hline Regulation (EU) 2019/943 allows the \\
implementation of a capacity mechanism as \\
a measure of last resort.
\end{tabular}

Regulation (EU) 2019/943 requires Member States to conduct a study of the effect on neighbouring Member States.

Regulation (EU) 2019/943 gives priority to strategic reserves implementation.

Regulation (EU) 2019/943 includes a provision on the phasing-out of capacity mechanisms.

Regulation (EU) 2019/943 specifies that capacity mechanisms are temporary.

Regulation (EU) 2019/943 includes measures on already existing capacity mechanisms.

\section{Section 7.3.2}

Regulation (EU) 2019/943 provides general design principles for capacity mechanisms.
Relevant article

Art. 21(1) states that 'to eliminate residual resource adequacy concerns, Member States may, as a last resort while implementing the measures referred to in Article 20(3) of this Regulation in accordance with Article 107, 108 and 109 of the TFEU, introduce capacity mechanisms.'

Art. 21(2) states that 'before introducing capacity mechanisms, the Member States concerned shall conduct a comprehensive study of the possible effects of such mechanisms on the neighbouring Member States by consulting at least its neighbouring Member States to which they have a direct network connection and the stakeholders of those Member States.'

Art. 21(3) requires that Member States give priority to capacity mechanisms in the form of strategic reserves. It states that 'Member States shall assess whether a capacity mechanism in the form of strategic reserve is capable of addressing the resource adequacy concerns. Where this is not the case, Member States may implement a different type of capacity mechanism.'

Art. 21(7) states that "when designing capacity mechanisms Member States shall include a provision allowing for an efficient administrative phase-out of the capacity mechanism where no new contracts are concluded under paragraph 6 during three consecutive years.'

Art. 21(8) states that capacity mechanisms are to be temporary.It adds that 'they shall be approved by the Commission for no longer than 10 years. They shall be phased out or the amount of the committed capacities shall be reduced on the basis of the implementation plans referred to in Article 20. Member States shall continue to apply the implementation plan after the introduction of the capacity mechanism.'

Regarding capacity mechanisms already in place, Art. 21(6) says that ${ }^{\text {t }}$ where a Member State applies a capacity mechanism, it shall review that capacity mechanism and shall ensure that no new contracts are concluded under that mechanism where both the European resource adequacy assessment and the national resource adequacy assessment, or in the absence of a national resource adequacy assessment, the European resource adequacy assessment have not identified a resource adequacy concern or the implementation plan as referred to in Article 20(3) has not received an opinion by the Commission as referred to in Article 20(5).'

Art. 22(1) enumerates design principles for capacity mechanisms. It states that 'any capacity mechanism shall:

(a) be temporary;

(b) not create undue market distortions and not limit cross-zonal trade; 
Section of this chapter, topic and relevant regulation
Regulation (EU) 2019/943 provides specific design principles for strategic reserves.
Relevant article

(c) not go beyond what is necessary to address the adequacy concerns referred to in Article 20;

(d) select capacity providers by means of a transparent, non-discriminatory and competitive process;

(e) provide incentives for capacity providers to be available in times of expected system stress;

(f) ensure that the remuneration is determined through the competitive process;

(g) set out the technical conditions for the participation of capacity providers in advance of the selection process;

(h) be open to participation of all resources that are capable of providing the required technical performance, including energy storage and demand side management;

(i) apply appropriate penalties to capacity providers that are not available in times of system stress.'

Art. 22(2) specifies design principles for strategic reserves. It states that 'the design of strategic reserves shall meet the following requirements:

(a) where a capacity mechanism has been designed as a strategic reserve, the resources thereof are to be dispatched only if the transmission system operators are likely to exhaust their balancing resources to establish an equilibrium between demand and supply;

(b) during imbalance settlement periods where resources in the strategic reserve are dispatched, imbalances in the market are to be settled at least at the value of lost load or at a higher value than the intraday technical price limit as referred in Article 10(1), whichever is higher;

(c) the output of the strategic reserve following dispatch is to be attributed to balance responsible parties through the imbalance settlement mechanism; (d) the resources taking part in the strategic reserve are not to receive remuneration from the wholesale electricity markets or from the balancing markets;

(e) the resources in the strategic reserve are to be held outside the market for at least the duration of the contractual period.

The requirement referred to in point (a) of the first subparagraph shall be without prejudice to the activation of resources before actual dispatch in order to respect the ramping constraints and operating requirements of the resources. The output of the strategic reserve during activation shall not be attributed to balance groups through wholesale markets and shall not change their imbalances.' 


\begin{tabular}{ll}
\hline $\begin{array}{l}\text { Section of this chapter, topic and relevant } \\
\text { regulation }\end{array}$ & Relevant article \\
\hline $\begin{array}{l}\text { Regulation (EU) 2019/943 provides design } \\
\text { principles for mechanisms other than strategic }\end{array}$ & $\begin{array}{l}\text { For mechanisms other than strategic reserves, Art. 22(3) lists additional design } \\
\text { principles to those included in Art. 22(1). It states that' capacity mechanisms } \\
\text { reserves. }\end{array}$ \\
& $\begin{array}{l}\text { (a) be constructed so as to ensure that the price paid for availability } \\
\text { automatically tends to zero when the level of capacity supplied is expected to } \\
\text { be adequate to meet the level of capacity demanded; } \\
\text { (b) remunerate the participating resources only for their availability and } \\
\text { ensure that the remuneration does not affect decisions of the capacity provider } \\
\text { on whether or not to generate; } \\
\text { (c) ensure that capacity obligations are transferable between eligible capacity } \\
\text { providers.' }\end{array}$
\end{tabular}

Regulation (EU) 2019/943 sets emission limits for generation units to participate in capacity mechanisms. It differentiates between existing and new generation capacity and requires ACER to provide technical guidance on the emission limit values.

Regulation (EU) 2019/943 includes a grandfathering clause for capacity mechanism contracts concluded before 31 December 2019.

Regulation (EU) 2019/943 requires that capacity mechanisms are open for cross-border participation.
Art. 22(4) includes two limits on the $\mathrm{CO} 2$ emissions of generating units participating in capacity mechanisms. This is with regard to the start date of their commercial production. It states that 'capacity mechanisms shall incorporate the following requirements regarding $\mathrm{CO} 2$ emission limits: (a) from 4 July 2019 at the latest, generation capacity that started commercial production on or after that date and that emits more than $550 \mathrm{~g}$ of $\mathrm{CO} 2$ of fossil fuel origin per $\mathrm{kWh}$ of electricity shall not be committed or to receive payments or commitments for future payments under a capacity mechanism; (b) from 1 July 2025 at the latest, generation capacity that started commercial production before 4 July 2019 and that emits more than $550 \mathrm{~g}$ of CO2 of fossil fuel origin per $\mathrm{kWh}$ of electricity and more than $350 \mathrm{~kg} C O 2$ of fossil fuel origin on average per year per installed $k W e$ shall not be committed or receive payments or commitments for future payments under a capacity mechanism. The emission limit of $550 \mathrm{~g} \mathrm{CO} 2$ of fossil fuel origin per $\mathrm{kWh}$ of electricity and the limit of $350 \mathrm{~kg} C O 2$ of fossil fuel origin on average per year per installed $k$ We referred to in points (a) and (b) of the first subparagraph shall be calculated on the basis of the design efficiency of the generation unit meaning the net efficiency at nominal capacity under the relevant standards provided for by the International Organization for Standardization. By 5 January 2020, ACER shall publish an opinion providing technical guidance related to the calculation of the values referred in the first subparagraph.'

Art. 22(5) says that 'Member States that apply capacity mechanisms on 4 July 2019 shall adapt their mechanisms to comply with Chapter 4 without prejudice to commitments or contracts concluded by 31 December 2019.'

Art. 26(1) states that 'capacity mechanisms other than strategic reserves and where technically feasible, strategic reserves shall be open to direct cross-border participation of capacity providers located in another Member State, subject to the conditions laid down in this Article.' Art. 26(3) adds that 'Member States shall not prevent capacity which is located in their territory from participating in capacity mechanisms of other Member States.' 


\begin{tabular}{|c|c|}
\hline $\begin{array}{l}\text { Section of this chapter, topic and relevant } \\
\text { regulation }\end{array}$ & Relevant article \\
\hline $\begin{array}{l}\text { Regulation (EU) } 2019 / 943 \text { sets out the process } \\
\text { for the calculation of the maximum entry } \\
\text { capacity for participation by foreign capacity in } \\
\text { capacity mechanisms and the roles of the RCCs } \\
\text { and the TSOs. }\end{array}$ & $\begin{array}{l}\text { Art. 26(7) states that'for the purposes of providing a recommendation to } \\
\text { transmission system operators, regional coordination centres established } \\
\text { pursuant to Article } 35 \text { shall calculate on an annual basis the maximum entry } \\
\text { capacity available for the participation of foreign capacity. That calculation } \\
\text { shall take into account the expected availability of interconnection and } \\
\text { the likely concurrence of system stress in the system where the mechanism } \\
\text { is applied and the system in which the foreign capacity is located. Such } \\
\text { a calculation shall be required for each bidding zone border. } \\
\text { Transmission system operators shall set the maximum entry capacity available } \\
\text { for the participation of foreign capacity based on the recommendation of the } \\
\text { regional coordination centre on an annual basis.' }\end{array}$ \\
\hline $\begin{array}{l}\text { Regulation (EU) } 2019 / 943 \text { sets the } \\
\text { methodologies, rules and terms related } \\
\text { to cross-border participation in capacity } \\
\text { mechanisms. }\end{array}$ & $\begin{array}{l}\text { Art. 26(11) lists the different methodologies, common rules and terms to be } \\
\text { developed by ENTSO-E and submitted to ACER. It states that 'by } 5 \text { July } 2020 \\
\text { the ENTSO for Electricity shall submit to ACER: } \\
\text { (a) a methodology for calculating the maximum entry capacity for } \\
\text { cross-border participation as referred to in paragraph 7; } \\
\text { (b) a methodology for sharing the revenues referred to in paragraph 9; } \\
\text { (c) common rules for the carrying out of availability checks referred to in point } \\
\text { (b) of paragraph 10; } \\
\text { (d) common rules for determining when a non-availability payment is due; } \\
\text { (e) terms of the operation of the registry as referred to in point (a) of } \\
\text { paragraph } 10 \text {; } \\
\text { (f) common rules for identifying capacity eligible to participate in the capacity } \\
\text { mechanism as referred to in point (a) of paragraph 10.' }\end{array}$ \\
\hline
\end{tabular}

